IdeAs

Idées d'Amériques

5 | 2015

Crise ou transformations du monde du travail dans les Amériques

\title{
Les Lettres brésiliennes
}

Maria da Conceição Coelho Ferreira et Rita Olivieri-Godet

\section{(2) OpenEdition \\ Journals}

Édition électronique

URL : https://journals.openedition.org/ideas/977

DOI : $10.4000 /$ ideas. 977

ISSN : 1950-5701

Éditeur

Institut des Amériques

Référence électronique

Maria da Conceição Coelho Ferreira et Rita Olivieri-Godet, « Les Lettres brésiliennes », IdeAs [En ligne], 5 | 2015, mis en ligne le 11 juin 2015, consulté le 18 octobre 2022. URL : http://

journals.openedition.org/ideas/977; DOI : https://doi.org/10.4000/ideas.977

Ce document a été généré automatiquement le 18 octobre 2022

\section{(c) (i) () $\Theta$}

Creative Commons - Attribution - Pas d'Utilisation Commerciale - Pas de Modification 4.0 International - CC BY-NC-ND 4.0

https://creativecommons.org/licenses/by-nc-nd/4.0/ 


\section{Les Lettres brésiliennes}

Maria da Conceição Coelho Ferreira et Rita Olivieri-Godet 
Pour la deuxième fois depuis 1998, le Brésil était l'invité d'honneur du Salon du Livre de Paris en cette édition 2015, avec la présence d'une importante délégation brésilienne estimée à 150 personnes entre auteurs, éditeurs et libraires. Plus de quarante écrivains, toutes générations, thématiques et styles confondus, ont participé au programme de dédicaces ainsi qu'au programme alléchant de rencontres thématiques du stand du Brésil (L 70), proposé par Guiomar de Grammont, écrivain et enseignant-chercheur de l'Université Fédérale de Ouro Preto-Minas Gerais, conseillère et coordinatrice de la participation du Brésil au Salon du livre. Etant donné l'ampleur de l'événement, l'éditeur Michel Chandeigne l'a surnommé l' « avalanche brésilienne ».

Il était temps de remettre la littérature brésilienne à l'honneur en France. Pendant quatre jours, les Français ont pu faire plus ample connaissance avec les auteurs présents et avec un large éventail thématique en phase avec la diversité de la production littéraire brésilienne contemporaine. Animés par des enseignantschercheurs, éditeurs et autres connaisseurs de ce domaine, les temps forts du programme ont eu lieu au stand de l'Ambassade du Brésil, dans les locaux de la CNL, ou encore dans l'amphithéâtre ouvert appelé Place des Auteurs.

Le Brésil est le premier pays à être, pour la deuxième fois, mis à l'honneur au Salon $d u$ Livre de Paris, ce qui témoigne de l'importance de sa présence dans l'imaginaire social français et de l'intérêt grandissant de la France pour la culture et la littérature brésiliennes. Des événements culturels comme l'année du Brésil en France (2005) et l'année de la France au Brésil (2009) ont certainement contribué à nourrir les échanges culturels entre ces deux pays. Le Salon a offert au public français la chance de découvrir ou de revisiter des œuvres qui donnent accès aux multiples facettes de ce grand pays du continent sud-américain ainsi qu'à de nouvelles lignes de force thématiques (violence et dégradation urbaine, mémoire et histoire des vaincus, perte de repères et solitude de l'homme moderne, mobilités sociales, minorités ethniques...) et formelles (effacement des frontières de genres, multiplicité des voix narratives, inscription de l'oralité, hypermimétisme...) de l'écriture de la contemporanéité brésilienne.

\section{AUTEURS}

\section{MARIA DA CONCEIÇÃO COELHO FERREIRA}

Maria da Conceição Coelho Ferreira est maître de conférences à l'Université Lumière Lyon 2 et membre du Centre de recherches Langues et Cultures Européennes (LCE). Responsable de la licence de Portugais, elle est le référent pour le Brésil auprès de la Division des Relations Internationales de Lyon 2. Titulaire d'un doctorat de l'Université Sorbonne Nouvelle-Paris III sur l'œuvre de João Guimarães Rosa, elle a publié plusieurs articles dans des revues nationales et internationales et participe régulièrement à des colloques internationaux sur les littératures d'expression portugaise en France et à l'étranger. Ses travaux portent sur l'œuvre de João 
Guimarães Rosa et la littérature brésilienne contemporaine en général. Actuellement ses recherches se concentrent sur l'axe « Mémoire et Littérature ».

\section{RITA OLIVIERI-GODET}

Rita Olivieri-Godet nasceu na Bahia. Graduada em Letras (português-francês) pela Universidade Federal da Bahia, com doutorado em Teoria literária e literatura comparada pela Universidade de São Paulo e pós-doutorado em literatura comparada em Paris X, foi professora titular de teoria literária na Universidade Estadual de Feira de Santana-Bahia (1980-1997) e Maître de conférences de literatura brasileira em Paris 8 (1998-2003). Atualmente é professora titular de literatura brasileira da Université Rennes 2 e membro do Institut Universitaire de France (promoção 2013). Autora de vários artigos e obras sobre a literatura brasileira contemporânea e as relações literárias interamericanas dentre as quais se destacam as publicações recentes: L'altérité amérindienne dans la fiction contemporaine des Amériques. Brésil, Argentine, Québec (Québec: PUL, 2015); Viva o povo brasileiro. A ficção de uma nação plural (São Paulo: é Realizações, 2014); Jorge Amado em letras e cores (ensaios de Olivieri-Godet; desenhos de Juraci Dórea, Feira de Santana-Bahia, UEFS Editora, 2014). 